\title{
Model Pembelajaran Berbasis Proyek (Project Based Learning) Sesuai Pembelajaran Abad 21 Bermuatan Tri Kaya Parisudha
}

\section{Heny Nirmayani1 ${ }^{*}$, Ni Putu Candra Prastya Dewi ${ }^{2}$}

1,2 PGSD, STAHN Mpu Kuturan, Singaraja, Indonesia

\section{ART I CLE I N F O}

\section{Article history:}

Received June 22, 2021

Revised June 30, 2021

Accepted August 14, 2021

Available online October 25, 2021

Kata Kunci:

Pembelajaran Abad 21, Project

Based Learning, Tri Kaya

Parisudha

Keywords:

21st Century Learning, Project

Based Learning, Tri Kaya

Parisudha

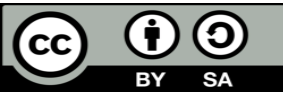

This is an open access article under the CC BY-SA license.

Copyright (C) 2021 by Author. Published by Universitas Pendidikan Ganesha.

\begin{abstract}
A B S T R A K
Masa pandemi membuat pembelajaran harus dilaksanakan secara daring sehingga guru harus memilih model pembelajaran yang tepat untuk siswa. Saat ini siswa kurang memiliki motivasi dalam belajar sehingga berdampak pada hasil belajar siswa yang rendah. Penelitian ini bertujuan untuk mengembangkan model Project Based Learning sesuai Pembelajaran Abad 21 bermuatan Tri Kaya Parisudha. Jenis penelitian ini yaitu penelitian pengembangan desain dan produk (Design and Development) dengan menggunakan Model ADDIE (Analysis, Design, Development, Implementation, and Evaluation). Subjek pada penelitian ini terdiri dari 2 orang ahli, 8 orang mahasiswa, dan 7 orang guru sekolah dasar. Metode pengumpulan data dengan cara observasi, wawancara, dan kuesioner. Instrument yang digunakan untuk mengumpulkan data yaitu kuesioner. Analisis kuantitatif untuk mengolah data hasil kuesioner yang kemudian disesuaikan dengan kateori PAIT. Hasil penelitian ini menunjukkan bahwa pengembangan model Project Based Learning sesuai Pembelajaran Abad 21 bermuatan Tri Kaya Parisudha berupa sintaks pembelajaran. Hasil validitas produk menyatakan bahwa pengembangan model Project Based Learning sesuai Pembelajaran Abad 21 bermuatan Tri Kaya Parisudha memiliki validitas yang sangat baik. Jadi model Project Based Learning sesuai Pembelajaran Abad 21 bermuatan Tri Kaya Parisudha layak untuk dijadikan panduan bagi guru sekolah dasar dalam melaksanakan pembelajaran. Model Project Based Learning bermuatan Tri Kaya Parisudha dapat membantu siswa dalam belajar.
\end{abstract}

\section{A B S T R A C T}

The pandemic period makes learning be carried out online, so teachers must choose the suitable learning model for students. Currently, students lack motivation in learning, so that the impact on student learning outcomes is low. This study aims to develop a Project-Based Learning model according to 21st Century Learning containing Tri Kaya Parisudha. This type of research is design and product development research (Design and Development) using the ADDIE Model (Analysis, Design, Development, Implementation, and Evaluation). The subjects in this study consisted of 2 experts, 8 students, and 7 elementary school teachers methods of collecting data using observation, interviews, and questionnaires. The instrument used to collect data is a questionnaire quantitative analysis to process the data from the questionnaire, which was then adjusted to the PAIT category. This study indicates that the development of the ProjectBased Learning model according to 21st Century Learning contains Tri Kaya Parisudha in the form of learning syntax. The results of the product validity state that the development of the Project-Based Learning model according to 21st Century Learning containing Tri Kaya Parisudha has very good validity. So the Project-Based Learning model, according to 21st Century Learning containing Tri Kaya Parisudha, is worthy of being used as a guide for elementary school teachers in carrying out learning. The project-Based Learning model containing Tri Kaya Parisudha can help students in learning.

\section{PENDAHULUAN}

Sistem pembelajaran di Indonesia masih perlu dikembangkan secara lebih komprehensif. Fenomena yang sering terjadi sering kali lulusan perguruan tinggi belum siap untuk memberikan pendidikan hanya karena menguasai teori, namun belum bisa diaplikasikan pada praktik pembelajarannya (Hikmawati et al., 2018; Yudiawan, 2020). Materi pun belum dikaitkan dengan budaya daerah sehingga karakter pun menjadi kurang terbentuk, karena hanya mengasah kemampuan kognitif saja (Cahyaningrum et al., 2017; Luthviyani et al., 2019). Perangkat pembelajaran yang terapkan selama ini merupakan hasil adopsi dari panduan perangkat secara nasional, sehingga banyak kendala yang dihadapi ketika berada dilapangan (Hidayatulloh et al., 2015; Salim Nahdi \& Cahyaningsih, 2018). 
Permasalahan yang dihadapi diantaranya, kurangnya kreativitas dan inovasi para pendidik untuk mengembangkan perangkat pembelajaran, dan tidak adanya proses evaluasi dan perbaikan perangkat pembelajaran oleh para pendidik (Nugroho, 2018; Nur Utami \& Mustadi, 2017). Mahasiswa sebagai calon pendidik harus mampu mengembangkan perangkat pembelajaran yang mengintegrasikan potensi kearifan lokal, agar materi yang diajarkan sesuai dengan potensi daerah dan konteks sosial masyarakat (Llosa \& Malone, 2017; Tanihardjo, 2016). Sehingga peserta didik mampu memecahkan masalah yang terkait dengan dunia nyata.

Hal ini menimbulkan permasalahan pembelajaran pada peserta didik, yaitu kurang memiliki motivasi dalam pembelajaran (Hosen et al., 2021; Lai \& Tai, 2021). Ditambah masa pandemi membuat pembelajaran harus dilaksanakan secara daring (Adedoyin \& Soykan, 2020; Lapitan et al., 2021). Apabila tidak dilakukan inovasi dalam pembelajaran, maka materi yang disampaikan oleh guru akan tidak dapat diserap atau diterima oleh siswa dengan baik. Oleh karena itu, diperluan sebuah inovasi pembelajaran yang harus dikembangan oleh guru (Balan et al., 2019; Lapitan et al., 2021; Sudaryono et al., 2020). Pembelajaran harus dapat meningatkan kemampuan berpikir kritis siwa (critical thinking), kemampuan berkomunikasi (communication), kemampuan bekerja sama (collaboration) dan kemampuan berkreatifitas (creativity) sesuai dengan keterampilan yang perlu dimiliki pada pembelajaran abad 21 (Luciana, 2020; Malik, 2018; Rusdin, 2018). Kemampuan ini perlu dimiliki siswa karena masa industry 4.0 yang canggih akan kemajuan teknologinya perlu secara selektif untuk menyeleksi informasi yang diperoleh sehingga diperlukan keterampilan 4C untuk menciptakan SDM yang bekualitas (Bedir, 2019; Kembara et al., 2018; Rusdin, 2018).

Salah satu yang dapat dilakukan yaitu dengan mengembangkan model pembelajaran Project Based Learning sesuai pembelajaran abad 21 bermuatan Tri Kaya Parisudha. Pembelajaran Berbasis Proyek sebagai pembelajaran yang menggunakan Proyek sebagai media dalam proses pembelajaran untuk mencapai kompetensi sikap, pengetahuan dan keterampilan (Chounta et al., 2017; Dumitrescu et al., 2014; Marzuki \& Basariah, 2017). Penekanan pembelajaran terletak pada aktivitas-aktivitas peserta didik untuk menghasilkan produk dengan menerapkan keterampilan meneliti, menganalisis, membuat, sampai dengan mempresentasikan produk pembelajaran berdasarkan pengalaman nyata (Irman \& Waskito, 2020; Pan et al., 2021; Wijayanti et al., 2016). Produk yang dimaksud adalah hasil proyek berupa barang atau jasa dalam bentuk desain, skema, karya tulis, karya seni, karya teknologi/prakarya, dan lain-lain. Melalui penerapan Pembelajaran Berbasis Proyek, peserta didik akan berlatih merencanakan, melaksanakan kegiatan sesuai rencana dan menampilkan atau melaporkan hasil kegiatan (Logan et al., 2021; Mutakinati et al., 2018). Dengan adanya pembelajaran berbasis proyek maka siswa dapat mengeksplor pengetahuannya dengan keterlibatan langsung pada pembelajaran (Potvin et al., 2021; Suranti et al., 2017). Pembelajaran berbasis proyek (Project Based Learning) akan efektif juga untuk meningkatkan kemampuan afektif siswa dengan memadukannya dengan kearifan lokal bali yaitu Tri Kaya Parisudha. Tri Kaya Parisudha adalah tiga dasar perilaku yang harus disucikan, yaitu pikiran, perkataan dan perbuatan (Priantini, 2020; Suryani et al., 2019). Landasan etika agama Hindu dipedomani oleh Tri Kaya Parisudha (tiga jenis perbuatan yang benar), antara lain berpikir yang benar (Manacika), berkata yang benar (Wacika), berbuat yang benar (Kayika) (Dewi et al., 2014; Priantini, 2020; Veronika, 2019).

Temuan penelitian sebelumnya menyatakan bahwa model pembelajaran project based learning dapat meningkatkan suasana belajar di kelas (Anjelina Putri et al., 2018; Nurtanto et al., 2019). Temuan penelitian lainnya juga menyatakan bahwa model pembelajaran project based learning dapat memudahkan siswa dalam belajar sehingga dapat meningkatkan hasil belajar siswa (Chao et al., 2017; Juliawan et al., 2017; Ratnawati et al., 2020). Penelitian lainnya juga menyatakan bahwa implementasi ajaran Tri Kaya Parisudha dapat meningkatkan karakter siswa (Artawan \& Ardiawan, 2018; Somawati \& Made, 2019; Widiasih, 2019). Dapat disimpulkan bahwa perpaduan model Project Based Learning sesuai pembelajaran abad 21 bermuatan Tri Kaya Parisudha didukung oleh penelitian Annafi mampu meningkatkan hasil belajar pengetahuan dan sikap mahasiswa. Belum adanya kajian mengenai Model Project Based Learning Bermuatan Tri Kaya Parisudha untuk siswa sekolah dasar. Tujuan penelitian ini yaitu untuk menganalisis Model Project Based Learning sesuai pembelajaran abad 21 Bermuatan Tri Kaya Parisudha. Diharapkan Model Project Based Learning Bermuatan Tri Kaya Parisudha dapat membantu siswa dalam belajar sehingga dapat meningkatkan hasil belajar siswa.

\section{METODE}

Desain pada penelitian ini adalah pengembangan desain dan produk (Design and Development) model ADDIE. Model ini terdiri lima komponen, yaitu: analisis (analysis), perancangan (design), pengembangan (development), implementasi (implementation), dan evaluasi (evaluation) (Alnajdi, 2018; Wulandari et al., 2020). Subjek penelitian ini adalah 2 orang dosen ahli, yaitu ahli konten dan ahli bahasa, 
5 orang guru SD di Kecamatan Buleleng; dan 5 mahasiswa PGSD STAHN Mpu Kuturan Singaraja. Metode yang digunakan untuk mengumpulkan data yaitu observasi, wawancara, dan kuesioner. Instrumen yang digunakan untuk mengumpulkan data yaitu lembar kuesioner. Adapun kisi-kisi instrument disajikan pada Tabel 1.

Tabel 1. Kisi-Kisi Instrumen Penelitian

\begin{tabular}{llll}
\hline No & \multicolumn{1}{c}{ Jenis Instrumen } & & \multicolumn{1}{c}{ Indikator } \\
\hline 1 & Instrumen Ahli Bahasa & 1. & Keterbacaan \\
& & 2. & Kesesuaian dengan kaidah Bahasa Indonesia yang baik dan \\
& & & benar \\
2 & Instrumen Ahli Konten & 1. & Keseluruhan \\
& & 2. & Legalitas \\
& & 3. & Materi/Substansi \\
& & 4. & Bahasa \\
& & 5. & Penyajian \\
& & 6. & Keseluruhan \\
4 & Instrumen Respon Guru dan & 1. & Bahasa dan Penulisan \\
& siswa & 2. Isi \\
& 3. & Kebermanfaatan \\
\hline
\end{tabular}

Sumber data pada penelitian ini terdiri atas data primer dan data sekunder. Data primer berupa hasil kuesioner yang diberikan kepada subjek penelitian dan wawancara dengan guru SD. Data sekunder berupa buku referensi. Data dan teknik pengumpulan data penelitian mencakup 3 dimensi penilaian, yaitu bahasa dan penulisan untuk ahli bahasa; komponen-komponen buku yang baik untuk ahli konten; dan kebermanfaatan atau aplikasi untuk mengetahui respons mahasiswa PGSD dan guru SD yang dikumpulkan dengan kuesioner. Teknik analisis data dilaksanakan secara deskriptif kuantitatif dan mengkonversi hasilnya sesuai kategori PAIT.

\section{HASIL DAN PEMBAHASAN}

Hasil

Pembelajaran Berbasis Proyek sebagai pembelajaran yang menggunakan Proyek sebagai media dalam proses pembelajaran untuk mencapai kompetensi sikap, pengetahuan dan keterampilan. Sintaks model pembelajaran yang menjadi dasar implementasi Project Based Learning sesuai pembelajaran abad 21 bermuatan Tri Kaya Parisudha pada penelitian ini disajikan pada Tabel 1.

Tabel 1. Sintaks Model Pembelajaran Project Based Learning Sesuai Pembelajaran Abad 21 Bermuatan Tri Kaya Parisudha

\begin{tabular}{|c|c|c|c|}
\hline No & Fase & Aktivitas Guru & Aktivitas Siswa \\
\hline 1 & $\begin{array}{l}\text { Start With the Essential } \\
\text { Question } \\
\text { Pertanyaan mendasar serta } \\
\text { penentuan projek } \\
\text { (critical thinking, } \\
\text { communication, Manacika, } \\
\text { Wacika) }\end{array}$ & $\begin{array}{l}\text { Guru memfasilitasi siswa untuk } \\
\text { bertanya terkait persiapan } \\
\text { tema/topik suatu proyek }\end{array}$ & $\begin{array}{l}\text { Siswa mengajukan pertanyaan } \\
\text { sebagai bahan tema/topik } \\
\text { proyek yang akan dibuat }\end{array}$ \\
\hline 2 & $\begin{array}{l}\text { Design a Plan for the Project } \\
\text { Perancangan langkah-langkah } \\
\text { penyelesaian proyek } \\
\text { (critical thinking, } \\
\text { communication, Manacika, } \\
\text { Wacika) }\end{array}$ & $\begin{array}{l}\text { Guru memfasilitasi peserta } \\
\text { didik untuk merancang } \\
\text { langkah-langkah kegiatan } \\
\text { penyelesaian proyek beserta } \\
\text { pengelolaannya }\end{array}$ & $\begin{array}{l}\text { Siswa merancang langkah- } \\
\text { langkah kegiatan penyelesaian } \\
\text { proyek beserta pengelolaannya }\end{array}$ \\
\hline 3 & $\begin{array}{l}\text { Create a Schedule } \\
\text { Penyusunan jadwal } \\
\text { pelaksanaan proyek } \\
\text { (critical thinking, }\end{array}$ & $\begin{array}{l}\text { Guru memberikan } \\
\text { pendampingan kepada peserta } \\
\text { didik melakukan penjadwalan } \\
\text { semua kegiatan yang telah }\end{array}$ & $\begin{array}{l}\text { Siswa melakukan penjadwalan } \\
\text { semua kegiatan yang telah } \\
\text { dirancangnya }\end{array}$ \\
\hline
\end{tabular}




\begin{tabular}{|c|c|c|c|}
\hline No & Fase & $\begin{array}{l}\text { Aktivitas Guru } \\
\end{array}$ & Aktivitas Siswa \\
\hline & $\begin{array}{l}\text { communication, Manacika, } \\
\text { Wacika) }\end{array}$ & dirancangnya & \\
\hline 4 & $\begin{array}{l}\text { Monitor the Students and the } \\
\text { Progress of the Project } \\
\text { Penyelesaian proyek dengan } \\
\text { difasilitasi dan monitoring guru } \\
\text { (collaboration dan creativity, } \\
\text { Kayika) }\end{array}$ & $\begin{array}{l}\text { Guru memfasilitasi dan } \\
\text { memonitor peserta didik } \\
\text { dalam melaksanakan } \\
\text { rancangan proyek yang telah } \\
\text { dibuat }\end{array}$ & $\begin{array}{l}\text { Siswa melaksanakan } \\
\text { rancangan proyek yang telah } \\
\text { dibuat }\end{array}$ \\
\hline 5 & $\begin{array}{l}\text { Assess the Outcome } \\
\text { Penyusunan laporan dan } \\
\text { presentasi/publikasi hasil } \\
\text { proyek } \\
\text { (collaboration, communication, } \\
\text { Kayika, Wacika) }\end{array}$ & $\begin{array}{l}\text { Guru memfasilitasi peserta } \\
\text { didik untuk Menyusun laporan } \\
\text { kemudian mempresentasikan } \\
\text { dan mempublikasikan hasil } \\
\text { karya }\end{array}$ & $\begin{array}{l}\text { Siswa Menyusun laporan } \\
\text { kemudian mempresentasikan } \\
\text { dan mempublikasikan hasil } \\
\text { karya }\end{array}$ \\
\hline 6 & $\begin{array}{l}\text { Evaluate the Experience } \\
\text { Evaluasi proses dan hasil } \\
\text { projek } \\
\text { (communication, Wacika) }\end{array}$ & $\begin{array}{l}\text { Guru dan peserta didik pada } \\
\text { akhir proses pembelajaran } \\
\text { melakukan refleksi terhadap } \\
\text { aktivitas dan hasil tugas proyek }\end{array}$ & $\begin{array}{l}\text { Siswa dan guru melakukan } \\
\text { refleksi terhadap aktivitas dan } \\
\text { hasil tugas proyek }\end{array}$ \\
\hline
\end{tabular}

Setelah dilakukan pengembangan produk, selanjutnya pengembangan ini diuji validitasnya dengan memberikan kuesioner kepada ahli bahasa dan ahli konten. Kemudian melakukan uji coba terbatas pada mahasiswa prodi PGSD dan guru SD untuk mengetahui respons terhadap pengembangan model Project Based Learning sesuai pembelajaran abad 21 bermuatan Tri Kaya Parisudha. Berdasarkan penilaian yang diberikan oleh ahli bahasa mengenai model Project Based Learning sesuai pembelajaran abad 21 bermuatan Tri Kaya Parisudha, dari aspek keterbacaan mendapatkan skor 3,5 sehingga mendapatkan kategori sangat baik. Aspek Kesesuaian dengan kaidah Bahasa Indonesia yang baik dan benar mendapatkan nilai 3,4 sehingga mendapatkan kategori sangat baik. Dari aspek keseluruhan mendapatkan skor 3,46 sehingga mendapatkan kategori sangat baik.

Hasil penilaian yang diberikan oleh ahli konten mengenai model Project Based Learning sesuai pembelajaran abad 21 bermuatan Tri Kaya Parisudha, dari aspek legalitas mendapatkan skor 3,00 sehingga sehingga mendapatkan kategori sangat baik. Aspek norma mendapatkan skor 4,00 sehingga mendapatkan kategori sangat baik. Aspek materi/substansi mendapatkan skor 3,71 sehingga mendapatkan kategori sangat baik. Dari aspek bahasa mendapatkan skor 3,67 sehingga mendapatkan kategori sangat baik. Aspek penyajian mendapatkan skor 3,83 sehingga mendapatkan kategori sangat baik. Dari aspek keseluruhkan mendapatkan skor 3,65 sehingga mendapatkan kategori sangat baik. Berdasarkan hasil uji validasi kedua tabel di atas, pengembangan model Project Based Learning sesuai pembelajaran abad 21 bermuatan Tri Kaya Parisudha yang dihasilkan pada penelitian ini memperoleh kategori sangat baik. Ini menunjukkan, hasil pengembangan model Project Based Learningsesuai pembelajaran abad 21 bermuatan Tri Kaya Parisudha sangat layak untuk digunakan untuk meningkatkan kualitas pembelajaran di sekolah dasar.

Setelah dilakukan uji validitas ahli Bahasa, selanjutnya dilakukan uji coba terbatas dengan pemberian kuesioner terhadap 8 mahasiswa PGSD STAHN Mpu Kuturan Singaraja dan 7 guru SD di Kecamatan Buleleng untuk memperoleh respons terhadap produk pengembangan yang telah dihasilkan. Hasil respon guru SD dari aspek bahasa dan penulisan mendapatkan skor 3,37 sehingga mendapatkan kategori sangat baik. Dari aspek isi mendapatkan skor 3,29 sehingga mendapatkan kategori sangat baik. Dari aspek kebermanfaatan mendapatkan skor 3,47 sehingga mendapatkan kategori sangat baik. Dapat disimpulkan bahwa penilaian yang diberikan oleh guru terhadap model Project Based Learning sesuai pembelajaran abad 21 bermuatan Tri Kaya Parisudha sangat baik. Hasil respon siswa dari aspek bahasa dan penulisan mendapatkan skor 3,58 sehingga sehingga mendapatkan kategori sangat baik. Dari aspek isi mendapatkan skor 3,33 sehingga mendapatkan kategori sangat baik. Dan dari aspek kebermanfaatan mendapatkan skor 3,46 sehingga mendapatkan kategori sangat baik. Berdasarkan hasil respon guru dan siswa pengembangan model Project Based Learning sesuai pembelajaran abad 21 bermuatan Tri Kaya Parisudha memiliki tingkat kevalidan sangat baik.

\section{Pembahasan}

Hasil penelitian menunjukkan bahwa model Project Based Learning sesuai pembelajaran abad 21 bermuatan Tri Kaya Parisudha sangat relevan digunakan dan diterapkan untuk meningkatkan kualitas proses pembelajaran. Hal ini didukung pula oleh komentar dari guru mengenai pengembangan produk 
secara umum yaitu pengembangan ini memberikan manfaat bagi guru untuk menerapkan pembelajaran inovatif nantinya sehingga siswa tidak mudah bosan dalam belajar (Marzuki \& Basariah, 2017; Pan et al., 2021; Wijayanti et al., 2016). Selain itu, integrasi dengan Tri Kaya Parisudha memberikan penanaman karakter kepada siswa sehingga tidak hanya kemampuan kognitif yang dikembangkan, namun juga kemampuan afektif dan psikomotor siswa (Priantini, 2020; Suryani et al., 2019). Model ini yaitu sintaks model ini dapat diterapkan pada RPP kurikulum 2013 sebagai persiapan pembelajaran bagi guru. Dengan sintaks pada model ini dapat merangsang keterlibatan aktif siswa dalam mengikuti pembelajaran sehingga nantinya pembelajaran akan bermakna bagi siswa (Irman \& Waskito, 2020; Laili et al., 2019; Wijayanti et al., 2016). Hal ini sesuai dengan teori belajar bermakna dari ausubel yang menyatakan bahwa pembelajaran akan menjadi bermakna apabila dikaitkan dengan kehidupan sehari-hari siswa (Mulyadi, 2016).

Melalui pembelajaran berbasis proyek ini tentunya siswa diarahkan untuk menghasilkan suatu proyek dalam pembelajaran. Proyek tersebutlah yang perlu dikaitkan dengan lingkungan sekitar anak. Hal ini menjadikan pembelajaran akan diingat lama dan tersimpan dalam memori jangka panjang anak (Mutakinati et al., 2018; Potvin et al., 2021). Pembelajaran dengan berbasis proyek juga mampu meningkatkan keterampilan siswa dalam berpikir kritis (critical thinking) dan kreativitas (creativity) karena harus membuat suatu proyek yang baik sesuai arahan guru (Suranti et al., 2017; Syafrijal \& Desyandri, 2019). Selain itu kemampuan bekerjasama (collaboration) siswa dalam pengerjaan proyek juga diasah dalam pembelajaran. Begitu juga dengan kemampuan berkomunikasi (communication) siswa akan diasah ketika ia menyampaikan hasil proyek yang telah dibuat bersama anggota kelompoknya. Inilah nantinya yang mengarahkan siswa pada peningkatan keterampilan 4C sebagai komponen pembelajaran abad 21 (Bedir, 2019; Kembara et al., 2018).

Namun agar siswa tetap memiliki karakter yang baik, pembelajaran perlu dikaitkan dengan kearifan local salah satunya Tri Kaya Parisudha yang terdiri dari Manacika (berpikir yang baik) yang diwujudkan ketika siswa berpikir kritis untuk merancang sebuah proyek, kemudian menjaga perkataan yang baik (Wacika) saat berkomunikasi (communicarion) dengan teman atau guru sehingga tercipta interaksi yang baik (Dewi et al., 2014; Priantini, 2020; Suryani et al., 2019). Tidak hanya itu, perbuatan yang baik (Kayika) perlu juga dijadikan landasan dalam berkreativitas (creativity) dan bekerjasama (collaboration) sehingga hasil atau proyek yang dibuat dapat diselesaikan dengan baik (Selamet, 2017; Somawati \& Made, 2019).

Tepatnya pengembangan pembelajaran berbasis proyek ini juga didukung oleh kelebihan model pembelajaran berbasis proyek yaitu meningkatkan motivasi belajar peserta didik untuk belajar, mendorong kemampuan mereka untuk melakukan pekerjaan penting, dan mereka perlu untuk dihargai (Dewi et al., 2018; Oksa \& Soenarto, 2020). Selain itu, model ini dapat meningkatkan kemampuan pemecahan masalah, membuat peserta didik menjadi lebih aktif dan berhasil memecahkan masalahmasalah yang kompleks, meningkatkan kolaborasi dan mendorong peserta didik untuk mengembangkan dan mempraktikkan keterampilan komunikasi (Dumitrescu et al., 2014; Marzuki \& Basariah, 2017; Susanti, 2013). Pembelajaran berbasis proyek menyediakan pengalaman belajar yang melibatkan peserta didik secara kompleks dan dirancang untuk berkembang sesuai dunia nyata (Chounta et al., 2017; Pan et al., 2021; Wijayanti et al., 2016).

Temuan penelitian sebelumnya juga menyatakan bahwa pembelajaran berbasis proyek dapat mengaktifkan siswa dalam belajar (Irman \& Waskito, 2020; Laili et al., 2019). Temuan penelitian sebelumnya juga menyatakan bahwa pembelajaran berbasis proyek dapat meningkatkan motivasi siswa dalam belajar sehingga dapat meningkatkan kemampuan siswa (Logan et al., 2021; Mulyadi, 2016; Mutakinati et al., 2018). Selain itu penelitian lainnya juga menyatakan bahwa implementasi ajaran Tri Kaya Parisudha dapat meningkatkan hasil belajar siswa (Dewi et al., 2014; Priantini, 2020; Rai et al., 2014). Dapat disimpulkan bahwa model Project Based Learning sesuai pembelajaran abad 21 bermuatan Tri Kaya Parisudha dapat membantu siswa dalam belajar. Implikasi penelitian ini yaitu pembelajaran berbasis proyek siswa dapat berperan aktif dalam mengkonstruksi pengetahuannya sendiri melalui pembuatan suatu proyek tertentu yang nantinya akan dihubungkan menjadi sebuah konsep. Selain itu dalam pembelajaran berbasis proyek siswa diberikan keluasan berfikir serta siswa dapat mempraktikkan langsung teori yang diperolehnya sehingga dapat diterapkan nantinya dalam kehidupan nyata..

\section{SIMPULAN}

Hasil penilaian yang dilakukan oleh para ahli, guru dan siswa menunjukan bahwa model Project Based Learning sesuai pembelajaran abad 21 bermuatan Tri Kaya Parisudha sangat baik. Oleh karena itu pengembangan model Project Based Learning sesuai pembelajaran abad 21 bermuatan Tri Kaya Parisudha layak untuk diterapkan pada siswa dalam meningkatkan kualitas pembelajaran di sekolah. Model Project 
Based Learning sesuai pembelajaran abad 21 bermuatan Tri Kaya Parisudha dapat membantu siswa dalam belajar.

\section{DAFTAR PUSTAKA}

Adedoyin, O. B., \& Soykan, E. (2020). Covid-19 pandemic and online learning: the challenges and opportunities. In Interactive Learning Environments. https://doi.org/10.1080/10494820.2020.1813180.

Alnajdi, S. M. (2018). The Effectiveness of Designing and Using a Practical Interactive Lesson based on ADDIE Model to Enhance Students' Learning Performances in University of Tabuk. Journal of Education and Learning, 7(6), 212. https://doi.org/10.5539/jel.v7n6p212.

Anjelina Putri, A. A., Swatra, I. W., \& Tegeh, I. M. (2018). Pengaruh Model Pembelajaran PBL Berbantuan Media Gambar Terhadap Hasil Belajar Ipa Siswa Kelas Iii Sd. Mimbar Ilmu, 23(1). https://doi.org/10.23887/mi.v23i1.16407.

Artawan, K. N., \& Ardiawan, I. K. N. (2018). Pembelajaran quantum Teaching berbasis Tri Kaya Parisudha. Edudikara: Jurnal Pendidikan Dan Pembelajaran, 3(2), 201-212. https://doi.org/10.32585/edudikara.v3i2.100.

Balan, L., Yuen, T., \& Mehrtash, M. (2019). Problem-Based Learning Strategy for CAD Software Using FreeChoice and Open-Ended Group Projects. Procedia Manufacturing, 32, 339-347. https://doi.org/10.1016/j.promfg.2019.02.223.

Bedir, H. (2019). Pre-service ELT teachers' beliefs and perceptions on 21st century learning and innovation skills (4Cs). Journal of Language and Linguistic Studies, 15(1), 231-246. https://doi.org/10.17263/jlls.547718.

Cahyaningrum, E. S., Sudaryanti, S., \& Purwanto, N. A. (2017). Pengembangan Nilai-Nilai Karakter Anak Usia Dini Melalui Pembiasaan Dan Keteladanan. Jurnal Pendidikan Anak, 6(2), 203-213. https://doi.org/10.21831/jpa.v6i2.17707.

Chao, J. Y., Tzeng, P. W., \& Po, H. Y. (2017). The study of problem solving process of e-book PBL course of atayal senior high school students in Taiwan. Eurasia Journal of Mathematics, Science and Technology Education, 13(3), 1001-1012. https://doi.org/10.12973/eurasia.2017.00654a.

Chounta, I. A., Manske, S., \& Hoppe, H. U. (2017). Correction to: "From Making to Learning": introducing Dev Camps as an educational paradigm for Re-inventing Project-based Learning (International Journal of Educational Technology in Higher Education, 10.1186/s41239-017-0061-2). International Journal of Educational Technology in Higher Education, 14(1), 41239. https://doi.org/10.1186/s41239-017-0079-5.

Dewi, Gading, \& Antara. (2018). Pengaruh Metode Pembelajaran Berbasis Proyek Terhadap Kemampuan Kerjasama Pada Anak Kelompok B Taman Kanak-Kanak. Jurnal Pendidikan Anak Usia Dini, 6(3). https://doi.org/10.23887/paud.v6i1.15184.

Dewi, N. K. C., Sedanayasa, G., \& Sulastri, M. (2014). Pengaruh Moidel Pembelajaran Numbered Head Together Berlandasakan Tri Kaya Parisudha Terhadap Hasil Belajar IPA Siswa Kelas V. Mimbar Pgsd Universitas Pendidikan Ganesha, 2(1). https://doi.org/10.23887/jjpgsd.v2i1.4144.

Dumitrescu, C., Olteanu, R. L., Gorghiu, L. M., \& Gorghiu, G. (2014). Learning Chemistry in the Frame of Integrated Science Modules - Romanian Student's Perception. Procedia - Social and Behavioral Sciences, 116(September 2015), 2516-2520. https://doi.org/10.1016/j.sbspro.2014.01.603.

Hidayatulloh, M., Humairoh, F., Wachidah, U., Iswati, D. A., \& Suliyanah, S. (2015). Pengembangan Perangkat Pembelajaran Untuk Mereduksi miskonsepsi Siswa Pada Materi Rangkaian Listrik Dengan Saintific Approach. Jurnal Penelitian IPA Dan Aplikasinya, 5(1). https://doi.org/10.26740/jpfa.v5n1.p28-32.

Hikmawati, H., Jufri, A. W., \& Sutrio. (2018). Simulasi Kegiatan Lesson Study Sebagai Upaya Untuk Mengembangkan Profesionalisme Pendidik. Jurnal Pendidikan Dan Pengabdian Masyarakat, 1(2).

Hosen, M., Ogbeibu, S., Giridharan, B., Cham, T.-H., Lim, W. M., \& Paul, J. (2021). Individual motivation and social media influence on student knowledge sharing and learning performance: Evidence from an emerging economy. Computers \& Education, 72. https://doi.org/10.1016/j.compedu.2021.104262.

Irman, S., \& Waskito, W. (2020). Validasi Modul Berbasis Project Based Learning pada Mata Pelajaran Simulasi dan Komunikasi Digital. Jurnal Ilmiah Pendidikan Dan Pembelajaran, 4(2), 260-269. https://doi.org/10.23887/jipp.v4i2.26156.

Juliawan, G. A., Mahadewi, L. P. P., \& Rati, W. R. (2017). Pengaruh Model Problem Based Learning (PBL) Terhadap Kemampuan Pemecahan Masalah Matematika. Mimbar PGSD, 5(2), 1-10. https://doi.org/10.23887/jjpgsd.v5i2.10881. 
Kembara, Rozak, \& Hadian. (2018). Research-based Lectures to Improve Students' 4C (Communication, Collaboration, Critical Thinking, and Creativity) Skills. Proceedings of the Second Conference on Language, Literature, Education, and Culture (ICOLLITE), 1(1). https://doi.org/10.2991/icollite$18.2019 .50, .20019 .11$.

Lai, C., \& Tai, C.-P. (2021). Types of social media activities and Hong Kong South and Southeast Asians Youth's Chinese language learning motivation. System, 97. https://doi.org/10.1016/j.system.2020.102432.

Laili, Ganefri, \& Usmeldi. (2019). Efektivitas Pengembangan E-Modul Project Based Learning pada Mata Pelajaran Instalasi Motor Listrik. Jurnal Ilmiah Pendidikan Dan Pembelajaran, 3(3). https://doi.org/10.23887/jipp.v3i3.21840. 306-309.

Lapitan, L. D., Tiangco, C. E., Sumalinog, D. A. G., Sabarillo, N. S., \& Diaz, J. M. (2021). An effective blended online teaching and learning strategy during the COVID-19 pandemic. Education for Chemical Engineers, 35(May 2020), 116-131. https://doi.org/10.1016/j.ece.2021.01.012.

Llosa, L., \& Malone, M. E. (2017). Student and instructor perceptions of writing tasks and performance on TOEFL iBT versus university writing courses. Assessing Writing, 34. https: //doi.org/10.1016/j.asw.2017.09.004.

Logan, R. M., Johnson, C. E., \& Worsham, J. W. (2021). Development of an E-learning Module to Facilitate Student Learning and Outcomes. Teaching and Learning in Nursing, 16(2), 139-142. https://doi.org/10.1016/j.teln.2020.10.007.

Luciana, N. L. R. (2020). Teachers' Readiness in Inserting the 21st Century Skills in the Lesson Plan in Teaching English. Jurnal Pendidikan Dan Pengajaran, 53(2), 168. https://doi.org/10.23887/jpp.v53i2.26406.

Luthviyani, Setianingsih, \& Handayani. (2019). Analisis Pelaksanaan Ekstrakurikuler Pramuka Terhadap Nilai-nilai Karakter Siswa di SD Negeri Pamongan. Jurnal Ilmiah Pendidikan Guru Sekolah Dasar, 12(2), 113-122. https://doi.org/10.33369/pgsd.12.2.113-122.

Malik, R. S. (2018). Educational Challenges in 21st Century and Sutainable Development. Journal of Sustainable Development Education and Research, 2(1), 9-20. https://doi.org/10.17509/jsder.v2i1.12266.

Marzuki, \& Basariah. (2017). The Influence Of Problem-Based Learning And Project Citizen Model In The Civic Education Learning On Student'scritical Thinking Ability And Self Discipline. Cakrawala Pendidikan, 6(3), 382-400. https://doi.org/10.21831/cp.v36i3.14675.

Mulyadi, E. (2016). Penerapan Model Project Based Learning untuk Meningkatan Kinerja dan Prestasi Belajar Fisika Siswa SMK. Jurnal Pendidikan Teknologi Dan Kejuruan, 22(4), 385. https://doi.org/10.21831/jptk.v22i4.7836.

Mutakinati, L., Anwari, I., \& Yoshisuke, K. (2018). Analysis of students' critical thinking skill of middle school through stem education project-based learning. Jurnal Pendidikan IPA Indonesia, 7(1), 5465. https://doi.org/10.15294/jpii.v7i1.10495.

Nugroho, R. (2018). Pengembangan Perangkat Pembelajaran Dengan Pendekatan Contextual Teaching And Learning Untuk Meningkatkan Motivasi Dan Hasil Belajar Bagi Siswa Kelas Iv Sekolah Dasar. Jurnal Bidang Pendidikan Dasar, 2(2). https://doi.org/10.21067/jbpd.v2i2.2638.

Nur Utami, K., \& Mustadi, A. (2017). Pengembangan Perangkat Pembelajaran Tematik Dalam Peningkatan Karakter, Motivasi, Dan Prestasi Belajar Siswa Sekolah Dasar. Jurnal Pendidikan Karakter, 7(1), 14-25. https://doi.org/10.21831/jpk.v7i1.15492.

Nurtanto, M., Sofyan, H., Fawaid, M., \& Rabiman, R. (2019). Problem-based learning (PBL) in industry 4.0: Improving learning quality through character-based literacy learning and life career skill (LLLCS). Universal Journal of Educational Research, 7(11), 2487-2494. https://doi.org/10.13189/ujer.2019.071128.

Oksa, S., \& Soenarto, S. (2020). Pengembangan E-Modul Berbasis Proyek Untuk Memotivasi Belajar Siswa Sekolah Kejuruan. Jurnal Kependidikan: Penelitian Inovasi Pembelajaran, 4(1), 99-111. https://doi.org/10.21831/jk.v4i1.27280.

Pan, G., Shankararaman, V., Koh, K., \& Gan, S. (2021). Students' evaluation of teaching in the project-based learning programme: An instrument and a development process. The International Journal of Management Education, 19(2). https://doi.org/10.1016/j.ijme.2021.100501.

Potvin, A. S., Boardman, A. G., \& Stamatis, K. (2021). Consequential change: Teachers scale project-based learning in English language arts. Teaching and Teacher Education, 107. https://doi.org/10.1016/j.tate.2021.103469.

Priantini, D. A. (2020). The Development Of Teaching Video Media Based On Tri Kaya Parisudha In Educational Psychology Courses. Journal of Education Technology, 4(4). https://doi.org/10.23887/jet.v4i4.29608. 
Rai, A. A. I., Dewi, M., \& Ganesha. (2014). Pengaruh Model Vct Berlandaskan Konsep Tri Kaya Siswa Kelas V Di Sd Gugus Iii Kecamatan Seririt 2013 / 2014. Jurnal Mimbar PGSD Universitas Pendidikan Ganesha, 2(1). https://doi.org/10.23887/jjpgsd.v2i1.2430.

Ratnawati, D., Handayani, I., \& Hadi, W. (2020). Pengaruh Model Pembelajaran PBL Berbantu Question Card terhadap Kemampuan Berpikir Kritis Matematis Siswa SMP. Edumatica: Jurnal Pendidikan Matematika, 10(01), 44-51.

Rusdin, N. M. (2018). Teachers' Readiness in Implementing 21st Century Learning. International Journal of Academic Research in Business and Social Sciences, 8(4), 1271-1284. https://doi.org/10.6007/IJARBSS/v8-i4/4270.

Salim Nahdi, D., \& Cahyaningsih, U. (2018). Pengembangan Perangkat Pembelajaran Matematika Sd Kelas V Dengan Berbasis Pendekatan Saintifik Yang Berorientasi Pada Kemampuan Pemecahan Masalah Siswa. Jurnal Cakrawala Pendas, 5(1), 1-7. https: //doi.org/10.31949/jcp.v5i1.1119.

Selamet, N. W. (2017). Pengaruh Model Pembelajaran Numbered Head Together Berbasis Tri Kaya Parisudha Terhadap Hasil Belajar IPS Siswa Kelas IV". E- Journal PGSD Universitas Pendidikan Ganesha. MIMBAR PGSD Undiksha, 5(2), 1-11. https://doi.org/10.23887/jjpgsd.v5i2.10768.

Somawati, A. V., \& Made, Y. A. D. N. (2019). Implementasi Ajaran Tri Kaya Parisudha Dalam Membangun Karakter Generasi Muda Hindu Di Era Digital. Jurnal Pasupati, 6(1). https://doi.org/10.37428/pspt.v6i1.135.

Sudaryono, Rahardja, U., \& Lutfiani, N. (2020). The Strategy of Improving Project Management Using Indicator Measurement Factor Analysis (IMF) Method. Journal of Physics: Conference Series, 1477(3). https://doi.org/10.1088/1742-6596/1477/3/032023.

Suranti, N. M. Y., Gunawan, G., \& Sahidu, H. (2017). Pengaruh Model Project Based Learning Berbantuan Media Virtual Terhadap Penguasaan Konsep Peserta didik pada Materi Alat-alat Optik. JPFT (Jurnal Pendidikan Fisika Dan Teknologi), 2(2). https://doi.org/10.29303/jpft.v2i2.292.

Suryani, N. K., Renda, N. T., \& Wibawa, I. M. C. (2019). Pengaruh Pendekatan Saintifik Berorientasi Tri Kaya Parisudha Terhadap Penguasaan Konsep Ipa Dan Keterampilan Proses Sains Siswa Kelas V Sd Di Gugus Vii Kecamatan Sukasada Kabupaten Buleleng Tahun Pelajaran 2018/2019. Journal of Education Technology. https://doi.org/10.23887/jet.v3i1.17962.

Susanti. (2013). Pengaruh Pembelajaran Berbasis Proyek Terhadap Kemampuan Berpikir Kreatif Dan Sikap Ilmiah Siswa Pada Materi Nutrisi. Jurnal Pembelajaran MIPA, 18(1). https://doi.org/10.18269/jpmipa.v18i1.254.

Syafrijal, \& Desyandri. (2019). Deveopment Of Integrated Thematic Teaching Materials With Project Based Learning Models In Class IV of Primary School. International Journal of Educational Dynamics/IJEDS, 1(2), 87-92. https://doi.org/10.24036/ijeds.v1i2.110.

Tanihardjo, J. (2016). The Analysis of Students' English Competence in the Grammar Section in the PaperBased TOEFL: A Case Study at English Department in Bunda Mulia University. Journal of English Language \& Culture, 6(1). https://doi.org/10.30813/jelc.v6i1.270.

Veronika, A. (2019). Implementasi Ajaran Tri Kaya Parisudha Dalam Membangun Karakter Generasi Muda Hindu Di Era Digital. Jurnal PASUPATI, 6(2). https: //doi.org/10.37428/pspt.v6i1.135.

Widiasih, L. S. (2019). Pengaruh Model Pembelajaran SFAE Berbasis Tri Kaya Parisudha terhadap Hasil Belajar Matematika Siswa. Jurnal Ilmiah Sekolah Dasar, 3(2). https://doi.org/10.23887/jisd.v3i2.17758.

Wijayanti, N. P. A., Damayanthi, L. P. E., Sunarya, I. M. G., \& Putrama, I. M. (2016). Pengembangan E-Modul Berbasis Project Based Learning Pada Mata Pelajaran Simulasi Digital Untuk Siswa Kelas X Studi Kasus di SMK Negeri 2 Singaraja. Jurnal Pendidikan Teknologi Dan Kejuruan, 13(2), 184-197. https://doi.org/10.23887/jptk-undiksha.v13i2.8526.

Wulandari, Sudatha, \& Simamora. (2020). Pengembangan Pembelajaran Blended Pada Mata Kuliah Ahara Yoga Semester II di IHDN Denpasar. Jurnal Edutech Undiksha, 8(1), 1-15. https://doi.org/10.23887/jeu.v8i1.26459.

Yudiawan, A. (2020). Belajar Bersama COVID 19: Evaluasi Pembelajaran Daring Era Pandemi di Perguruan Tinggi Keagamaan Islam Negeri, Papua Barat. Al-Fikr: Jurnal Pendidikan Islam, 6(1). https://doi.org/10.32489/alfikr.v6i1.64. 